\title{
LncRNA HOTTIP promotes the proliferation and invasion of ovarian cancer cells by activating the MEK/ERK pathway
}

\author{
JIAN LIU ${ }^{1}$, HONG-BO HU ${ }^{1}$, YAN-MING LIU ${ }^{2}$, FAN-XIANG LI ${ }^{1}$, LIU-PING ZHANG ${ }^{1}$ and ZONG-MIN LIAO ${ }^{1,3}$ \\ Departments of ${ }^{1}$ Gynaecology, ${ }^{2}$ Clinical Laboratory and ${ }^{3}$ Scientific Research and Education, \\ Yuebei People's Hospital, Shaoguan, Guangdong 512026, P.R. China
}

Received December 30, 2019; Accepted June 22, 2020

DOI: $10.3892 / \mathrm{mmr} .2020 .11452$

\begin{abstract}
Recent studies have revealed that long non-coding RNAs (lncRNAs) serve important roles in carcinogenesis and that this type of gene may be used as biomarkers in cancer. A high level of lncRNA HOXA distal transcript antisense RNA (HOTTIP) is associated with unfavorable prognosis for patients with ovarian cancer (OC), but the mechanism of HOTTIP involved in OC development remains to be elucidated. The present study aimed to investigate the mechanism of HOTTIP in metastasis-associated OC cell behaviors. HOTTIP levels in ovarian cells were quantified by reverse transcription-quantitative PCR, cell proliferation was analyzed by colony formation assay, and apoptosis was assessed by flow cytometry. Cell migratory and invasive abilities were evaluated by wound healing and Transwell assays, respectively. The expression levels of mitogen-activated protein kinase kinase (MEK)/ERK pathway-associated proteins were detected by western blotting. The results demonstrated that knockdown of HOTTIP in OC cells significantly reduced the phosphorylation levels of MEK and ERK, inhibited the proliferation and invasion of OC cells and promoted their apoptosis. Furthermore, the effects of HOTTIP on cell migration and invasion were partly associated with the epithelial-mesenchymal transition (EMT) process. Proliferation, invasion and EMT of OC cells were enhanced following overexpression of HOTTIP; however, these effects were reversed by the MEK/ERK pathway inhibitor U0126. In conclusion, HOTTIP was demonstrated to promote the proliferation, migration and invasion of $\mathrm{OC}$ cells by activating the MEK/ERK pathway. Therefore, HOTTIP may serve as a potential therapeutic target for OC.
\end{abstract}

Correspondence to: Dr Zong-Min Liao, Department of Gynaecology, Yuebei People's Hospital, 133 Huimin South Road, Shaoguan, Guangdong 512026, P.R. China

E-mail: liaozongmin639@163.com

Key words: long non-coding RNAs, HOXA distal transcript antisense RNA, ovarian cancer, mitogen-activated protein kinase kinase/ERK, epithelial-mesenchymal transition

\section{Introduction}

Among women, $\sim 2.5 \%$ of all malignant tumors are ovarian cancer (OC) (1), but OC accounts for $5 \%$ of cancer-associated mortality in female patients; this is due to the low survival rates, which are largely caused by the late-stage diagnosis of OC (2). At present, interval debulking surgery followed by platinum-based chemotherapy is the standard treatment for OC, but there remains a lack of methods for screening and early diagnosis of this disease (3). Thus, OC is usually diagnosed at a terminal stage, and it is important to study the mechanisms of OC carcinogenesis for improved diagnosis and treatment.

In the past decade, studies have uncovered the role of lncRNAs in carcinogenesis, suggesting that these genes may be used as promising biomarkers in cancer (4-6). Among them, IncRNA ANRIL is associated with an unfavorable prognosis and aggravates invasion in malignant OC (5), whereas lncRNA homeobox (HOX) A11-antisense suppresses the oncogenic phenotype of epithelial OC (6). Genes of the HOX family act as transcription factors that contribute to embryo and cancer development (7). HOXA distal transcript antisense RNA (HOTTIP) is an IncRNA that locates near chromosome $7 \mathrm{p} 15.2$ and transcribes from the 5 ' end of the HOXA gene (8). A previous study has revealed that HOTTIP regulates the stem cell characteristics of pancreatic cancer by regulating HOXA9 (9). Upregulation of HOTTIP promotes the invasion of esophageal squamous carcinoma cells by inducing epithelial-to-mesenchymal transition (EMT) (10). A previous study has also revealed that HOTTIP is an indicator of OC progression and enhances cell proliferation and invasion (11), but the underlying mechanism remains to be elucidated. However, downregulation of HOTTIP regulates the cell cycle and insulin secretion of islet $\beta$ cells by inhibiting the mitogen-activated protein kinase kinase (MEK)/ERK signaling pathway (12).

The present study hypothesized that HOTTIP may promote ovarian carcinogenesis by activating the MEK/ERK pathway.

\section{Materials and methods}

Cell culture. Human OC cell lines including OVCAR3, SKOV3 and human ovarian epithelial cells (HOSEpiC) were purchased from the American Type Culture Collection. The cells were cultured in Dulbecco's modified Eagle's medium (DMEM; 
Gibco; Thermo Fisher Scientific, Inc.) and supplemented with 10\% fetal bovine serum (FBS; Thermo Fisher Scientific, Inc.). The cells were cultured in a humidified atmosphere at $37^{\circ} \mathrm{C}$ with $5 \% \mathrm{CO}_{2}$.

Plasmids. HOTTIP short hairpin (sh)RNA (sh-HOTTIP) or negative controls (sh-NC) were obtained from Shanghai GenePharma Co., Ltd. A pcDNA3.1 vector (Invitrogen; Thermo Fisher Scientific, Inc.) was used for the construction of the overexpression plasmid pcDNA3.1-HOTTIP. The HOTTIP sequence (RefSeq, NR_037843.3) was purchased from Sangon Biotech Co., Ltd. and subcloned into the pcDNA3.1 vector; an empty pcDNA 3.1 vector was used as the control.

Cell transfection. OVCAR3 and SKOV3 cells were seeded in 6-well plates at the density of $1 \times 10^{6}$ cells/well, $2.5 \mu \mathrm{g}$ sh-HOTTIP or sh-NC was transfected into the cells for shRNA experiments and cells without transfection were used as control. 3.0 $\mu \mathrm{g}$ pcDNA3.1-HOTTIP or empty pcDNA3.1 (vector) was transfected into the cells for overexpression experiments and cells transfected vector were used as control. All the plasmids were transfected using Lipofectamine 2000 (Invitrogen; Thermo Fisher Scientific, Inc.) with Opti-MEM medium (Invitrogen; Thermo Fisher Scientific, Inc.) at $37^{\circ} \mathrm{C}$ for $48 \mathrm{~h}$. The medium was replaced by DMEM containing $2 \%$ FBS $6 \mathrm{~h}$ post transfection at $37^{\circ} \mathrm{C}$ according to the manufacturer's instructions. Cells were collected $48 \mathrm{~h}$ post-transfection, and HOTTIP expression levels were determined by reverse transcription-quantitative (RT-q PCR).

$R T$-qPCR. RNA extraction with TRIzol ${ }^{\circledR}$ (Invitrogen; Thermo Fisher Scientific, Inc.) from OVCAR3 or SKOV3 cells was carried out according to the manufacturer's protocol. The RNA was reverse-transcribed to cDNA at $42^{\circ} \mathrm{C}$ for $15 \mathrm{~min}$ with a cDNA synthesis kit (cat. no. AE341-02; TransGen Biotech Co., Ltd.) according to the manufacturer's instructions. QPCR was performed using a Roche Light-Cycler (Roche Diagnostics) whit a $\mathrm{SYBR}^{\circledR}$ Green Reaction mix (Qiagen $\mathrm{GmbH}$ ) under the following thermocycling conditions: Denaturation at $95^{\circ} \mathrm{C}$ for $15 \mathrm{sec}$ and annealing at $60^{\circ} \mathrm{C}$ for $30 \mathrm{sec}$, extension at $72^{\circ} \mathrm{C}$ for $30 \mathrm{sec}$ for a total of 40 cycles. The primers used were as follows: HOTTIP forward, 5'-AGCTCTTTTCCCCGACAG TG-3' and reverse, 5'-CCTTCACCAAGCTCCCTCTG-3'; and $\beta$-actin forward, 5'-ATTGCCGACAGGATGCAGAA-3' and reverse. 5'-GCTGATCCACATCTGCTGGA-3'. Experiments were performed in triplicate, the expression levels of HOTTIP were calculated and normalized to $\beta$-actin using the $2^{-\Delta \Delta \mathrm{Cq}}$ method (13).

Colony formation assay. OVCAR3 or SKOV3 cells ( 200 cells/well) were seeded in 6-well plates and cultured in complete DMEM for 14 days at $37^{\circ} \mathrm{C}$, culture medium changed regularly. Following washing with $\mathrm{PBS}$, the adherent colonies were fixed in cold $20 \%$ methanol at $4^{\circ} \mathrm{C}$ for $10 \mathrm{~min}$ and stained with $1 \%$ crystal violet (Sigma-Aldrich; Merck KGaA) dissolved in methanol for $15 \mathrm{~min}$ at room temperature. In some instances, $10 \mu \mathrm{M}$ U0126 (MedChemExpress) was added $12 \mathrm{~h}$ after the transfection to block MEK/ERK pathway selectively. The colonies were rinsed and counted under an inverted light microscope (magnification, $\mathrm{x} 40$ ).
Flow cytometry analysis of apoptosis. An Annexin V-FITC Detection kit (Beyotime Institute of Biotechnology) was used to detect apoptosis. OVCAR3 or SKOV3 cells grown in $6-\mathrm{cm}$ dishes at the density of $1 \times 10^{6}$ cells/well were harvested by trypsinization without EDTA and incubated with FITC-labelled Annexin $\mathrm{V}$ and propidium iodide (PI) according to the manufacturer's instructions. FlowJo version 10 software (FlowJo LLC) was used for analysis. The experiments were performed three times.

Western blotting. OVCAR3 or SKOV3 cells were harvested and lysed with ice cold RIPA buffer (Sigma-Aldrich; Merck $\mathrm{KGaA}$ ) supplemented with a protease inhibitor cocktail (Roche Diagnostics), which was used to extract the total protein. The lysates were centrifuged at $10,000 \mathrm{x}$ g for $10 \mathrm{~min}$ at $4^{\circ} \mathrm{C}$ to remove debris and the protein concentration was determined by BCA Kit (Takara Bio, Inc.). Cell lysate containing $20 \mu \mathrm{g}$ total protein samples was subjected to $10 \%$ SDS-PAGE and transferred to PVDF membranes (EMD Millipore). Following blocking with a BSA (BioFroxx)-TBST solution (1xTBS, 1\% Tween-20, $5 \% \mathrm{w} / \mathrm{v} \mathrm{BSA})$ for $1 \mathrm{~h}$ at room temperature, the membranes were incubated with primary antibodies (dilution 1:1,000) overnight at $4{ }^{\circ} \mathrm{C}$. The following antibodies were used: Anti-E-Cadherin (cat. no. 14472S), cleaved caspase-3 (cat. no. 9661S), total caspase-3 (cat. no. 9662S), phosphorylated (p-)p44/42 mitogen-activated protein kinase (MAPK; Erk1/2; Thr202/Tyr204; cat. no. 4370S) and p44/42 MAPK (Erk1/2; cat. no. 4695S), p-mitogen-activated protein kinase kinase (MEK)1/2 (Ser217/221; cat. no. 9154S), MEK1/2 (cat. no. 9122S), Bcl-2 (cat. no. 4223S) and Bax (cat. no. 14796S) from Cell Signaling Technologies, Inc; Ki67 (SP6; cat. no. GTX20833) from GeneTex, Inc.; proliferating cell nuclear antigen (PCNA; cat. no. 10205-2-AP), vimentin (cat. no. 10366-1-AP) and N-cadherin (cat. no. 22018-1-AP) from ProteinTech Group, Inc.; and SNAIL (Sn9H2, cat. no. ab229701) and $\beta$-actin (cat. no. ab179467) from Abcam. Primary antibody incubation was followed by incubation with a horseradish-peroxidase-conjugated secondary antibody (dilution 1:10,000; cat. no. ab205718, Abcam) at room temperature for $1 \mathrm{~h}$, and the protein blots on the membrane were imaged by chemiluminescence kit (Pierce; Thermo Fisher Scientific, Inc). Data were semi-quantified using ImageJ software v1.41 (National institutes of Health).

Cell invasion assay. Cell invasion was determined using Transwell invasion chambers with $8 \mu \mathrm{m}$ pores (BD Diagnostics) pre-coated with Matrigel overnight at $4^{\circ} \mathrm{C}$ according to the manufacturer's protocol. Briefly, $1 \times 10^{5}$ OVCAR3 or SKOV3 cells were transfected, resuspended in $200 \mu$ l DMEM without FBS and placed into the upper chamber of the insert with or without $10 \mu \mathrm{M}$ U0126. Complete DMEM medium plus $10 \%$ FBS was used as a chemoattractant in the lower chamber. The cells were incubated at $37^{\circ} \mathrm{C}$ for 1 day; subsequently, the cells on the back surface of the membrane were fixed with $20 \%$ methanol for $30 \mathrm{~min}$ at $4^{\circ} \mathrm{C}$ and stained with $0.1 \%$ crystal violet for $20 \mathrm{~min}$ at room temperature. The number of cells on the surface of the membrane was determined in five random fields of view using an IX71 inverted microscope (Olympus 

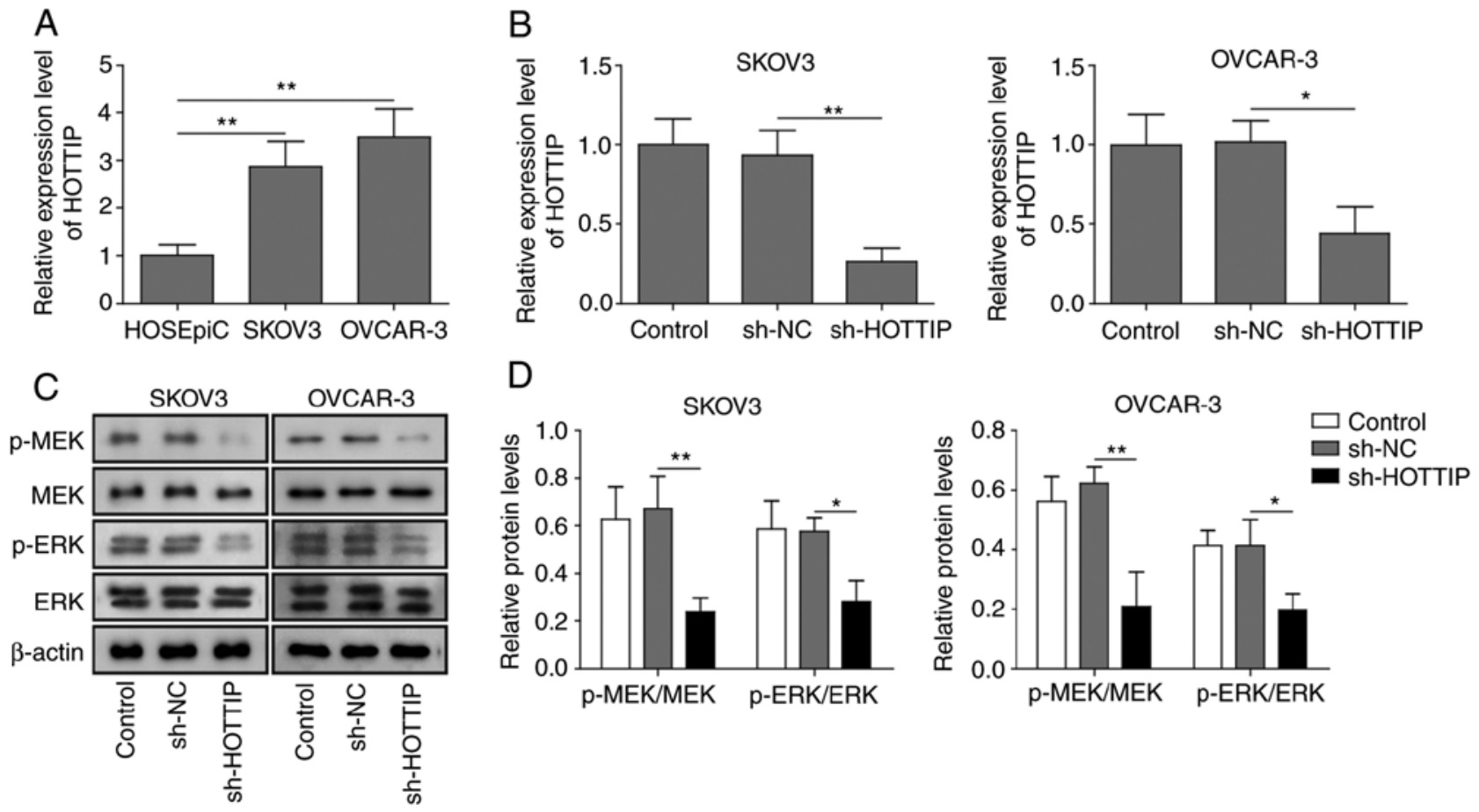

Figure 1. Knockdown of HOTTIP inhibits MEK/ERK signaling in ovarian cancer cells. (A) RT-qPCR analysis of HOTTIP expression levels in human ovarian cancer cell lines SKOV3 and OVCAR-3, and the human ovarian surface epithelial cell line HOSEpiC. (B) RT-qPCR analysis of HOTTIP in SKOV3 and OVCAR-3 cells transfected with sh-HOTTIP or sh-NC. (C and D) Western blotting analysis was performed to detect the expression of the MEK/ERK signaling pathway proteins in SKOV3 and OVCAR-3 cells following knockdown of HOTTIP. The data are presented as the mean \pm SD of three independent experiments. ${ }^{*} \mathrm{P}<0.05,{ }^{* *} \mathrm{P}<0.01$. HOTTIP, HOXA distal transcript antisense RNA; $\mathrm{p}-$, phosphorylated; MEK, mitogen-activated protein kinase kinase; RT-qPCR, reverse transcription-quantitative PCR; sh, short hairpin; NC, negative control.

Corporation), and images were captured at x200 magnification. The experiments were performed three times.

Cell migration assay. OVCAR3 or SKOV 3 cells $\left(2 \times 10^{6}\right)$ with or without transfection and $10 \mu \mathrm{M}$ U0126 were plated into a 6 -well plate and cultured in complete DMEM at $37^{\circ} \mathrm{C}$ until the cells were grown to confluence. Following a pre-incubation with $10 \mu \mathrm{g} / \mathrm{ml}$ mitomycin C (Sigma-Aldrich; Merck $\mathrm{KGaA}$ ) for $2 \mathrm{~h}$ at $37^{\circ} \mathrm{C}$, wounds were created in OC cell monolayers with a sterile $200 \mu \mathrm{l}$ pipette tip, and the medium was aspirated to remove the detached cells. Serum-free medium was added to the 6 -well plate, and images of the wound were captured at 0 and $24 \mathrm{~h}$. This experiment was performed three times. The wound area was analyzed in five random fields of view with an IX71 inverted microscope (Olympus Corporation) using AlphaImager 2200 software v3.2 (ProteinSimple).

Statistical analysis. The data are presented as the mean \pm standard deviation of three independent experiments. GraphPad Prism 5.0 (GraphPad Software, Inc.) was used for analysis. Statistical analyses were performed using one-way ANOVA with Tukey's post-hoc test. $\mathrm{P}<0.05$ was considered to indicate a statistically significant difference.

\section{Results}

Knockdown of HOTTIP inhibits the MEK/ERK pathway in OC cells. To explore the role of HOTTIP in OC progression, HOTTIP expression levels in human ovarian epithelial and OC cells were determined by RT-qPCR. SKOV3 and OVCAR-3 cells expressed higher levels of HOTTIP compared with HOSEpiC ovarian epithelial cells (Fig. 1A). To investigate the function of HOTTIP in OC cells, HOTTIP was knocked down by shRNA transfection. The expression of HOTTIP was significantly downregulated following transfection with sh-HOTTIP in SKOV3 and OVCAR-3 cells (Fig. 1B). In addition, HOTTIP knockdown reduced the levels of MEK and ERK phosphorylation compared with those in the cells transfected with sh-NC (Fig. 1C and D), which suggested that HOTTIP was involved in the MEK/ERK signaling transduction in human OC cells.

HOTTIP knockdown suppresses OC cell proliferation and promotes apoptosis. The MEK/ERK pathway serves an important role in regulating cell differentiation, proliferation, survival, migration and malignant transformation (14). In the present study, HOTTIP knockdown significantly reduced the proliferation of SKOV3 and OVCAR-3 cells (Fig. 2A and B). Furthermore, HOTTIP silencing promoted OC cell apoptosis as detected by Annexin V/PI staining (Fig. 2C and D). To further investigate the molecular mechanisms by which HOTTIP knockdown affected OC cell proliferation and apoptosis, protein markers of cell proliferation (PCNA and ki67) and apoptosis (cleaved caspase-3, Bax and Bcl-2) were analyzed by western blotting. The results demonstrated that knockdown of HOTTIP significantly reduced PCNA, ki67 and Bcl-2 protein levels, and elevated those of cleaved-caspase 3 and Bax in SKOV3 and OVCAR-3 cells compared with cells transfected with 
A

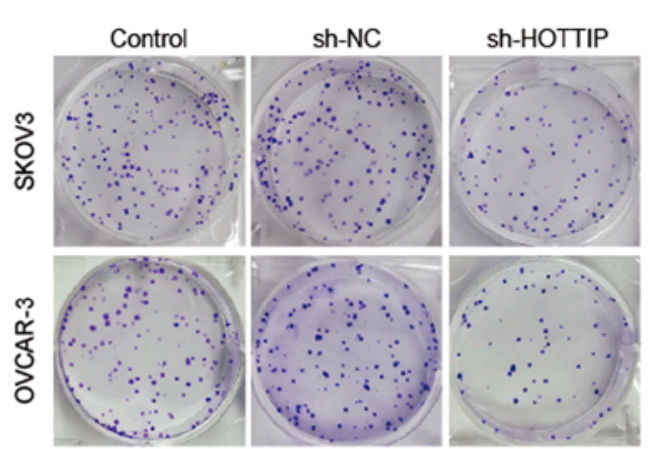

C
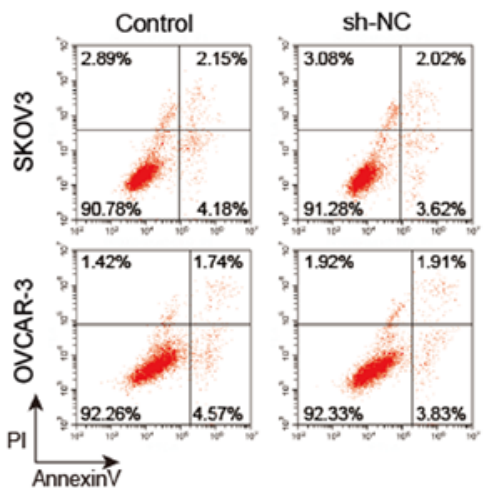

sh-HOTTIP
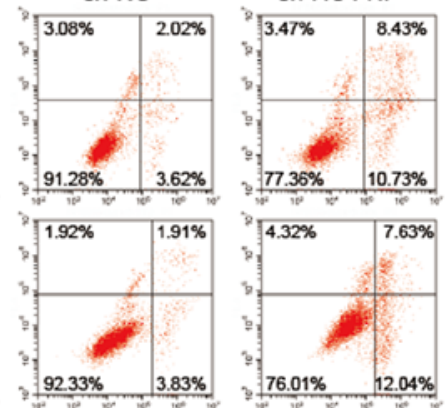

$9233 \% \quad 3.83 \%$

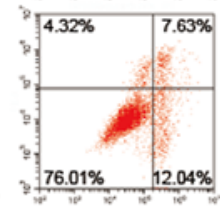

B

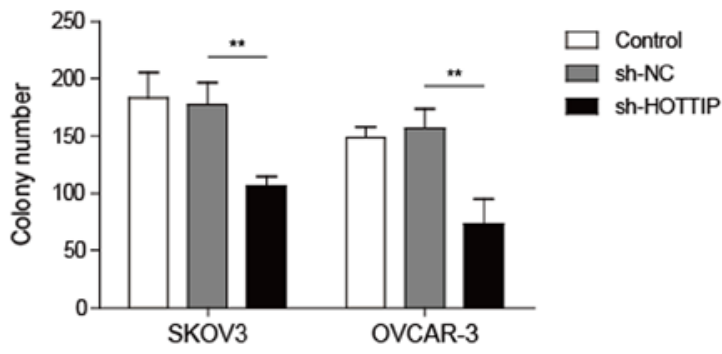

D

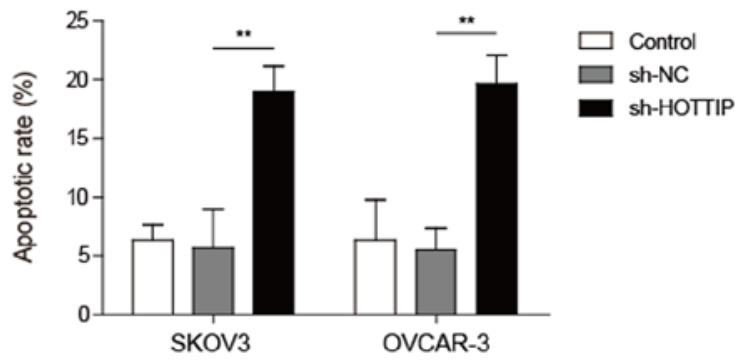

$\mathrm{E}$

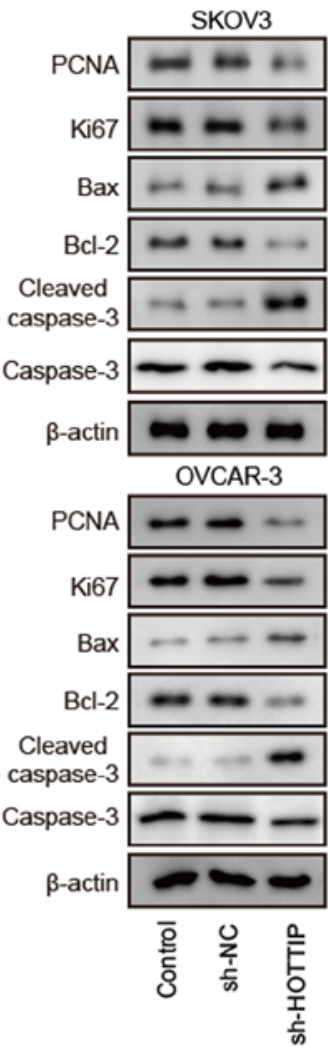

$\mathrm{F}$
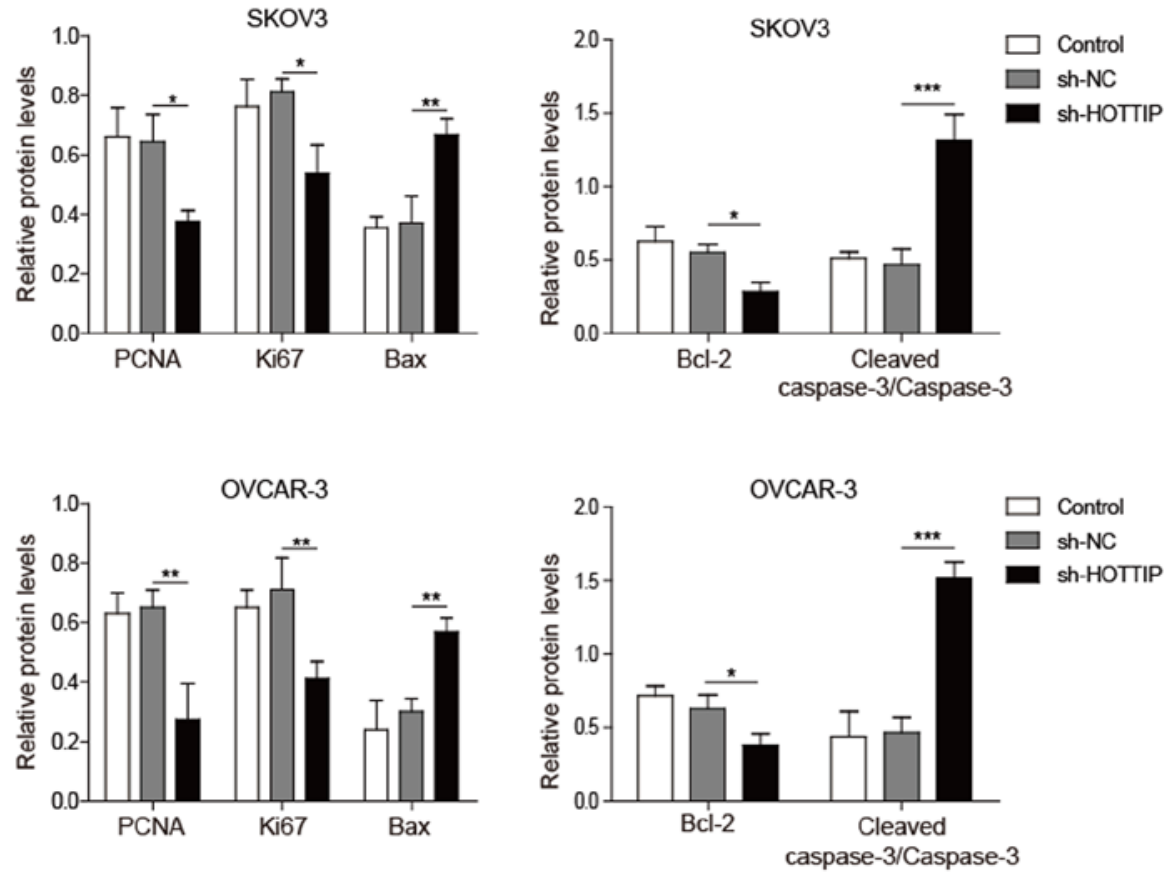

Figure 2. HOTTIP knockdown affects the proliferation and apoptosis of ovarian cancer cells. (A and B) Colony formation in SKOV3 and OVCAR-3 cells following transfection with sh-HOTTIP. (C and D) Apoptosis was determined by flow cytometric analysis in SKOV3 and OVCAR-3 cells transfected with sh-HOTTIP. (E and F) Western blotting detection of the expression of proliferation factors (PCNA and ki67) and apoptosis-associated proteins (cleaved caspase 3, Bax and Bcl-2) in transfected SKOV3 and OVCAR-3 cells, respectively. $\beta$-actin was used as internal control. The data are presented as the mean \pm SD of three independent experiments. ${ }^{*} \mathrm{P}<0.05,{ }^{* *} \mathrm{P}<0.01,{ }^{* * *} \mathrm{P}<0.001$. HOTTIP, HOXA distal transcript antisense RNA; sh, short hairpin; PCNA, proliferating cell nuclear antigen; $\mathrm{NC}$, negative control; PI, propidium iodide.

sh-NC (Fig. 2E and F). These results indicated that HOTTIP knockdown suppressed OC cell proliferation and promoted apoptosis.
HOTTIP knockdown inhibits OC cell migration, invasion and EMT. Metastasis is a major cause of poor outcomes in patients with cancer; thus, the effects of HOTTIP on 
A
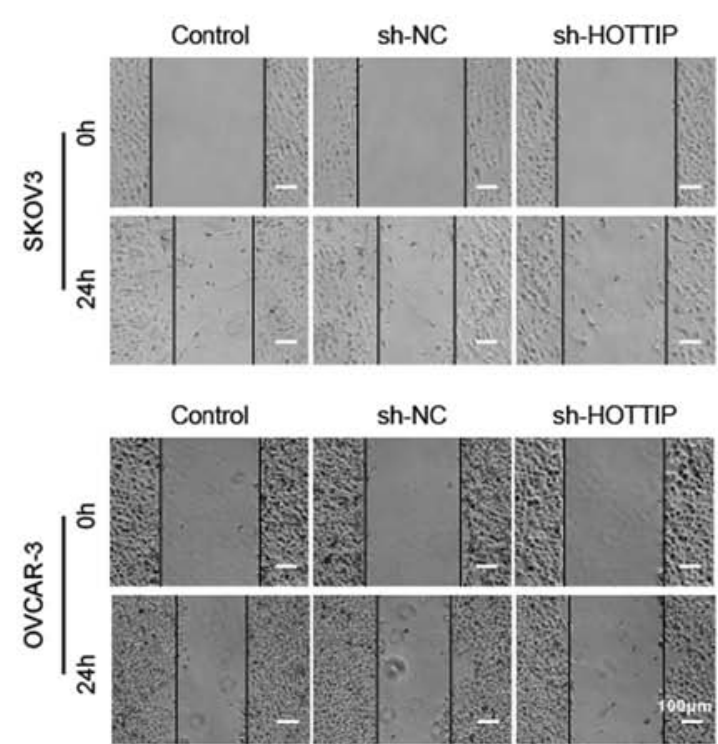

C

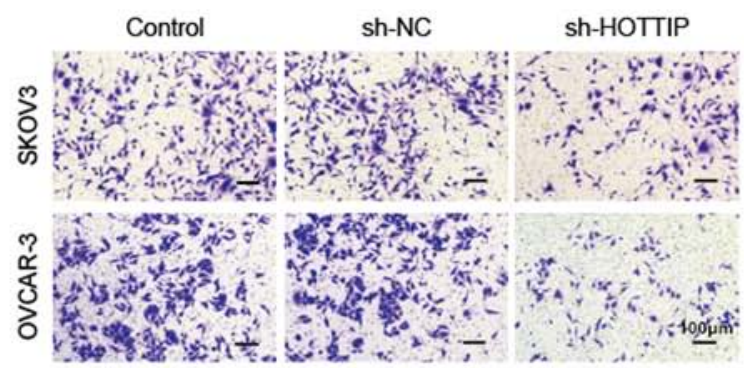

$E$

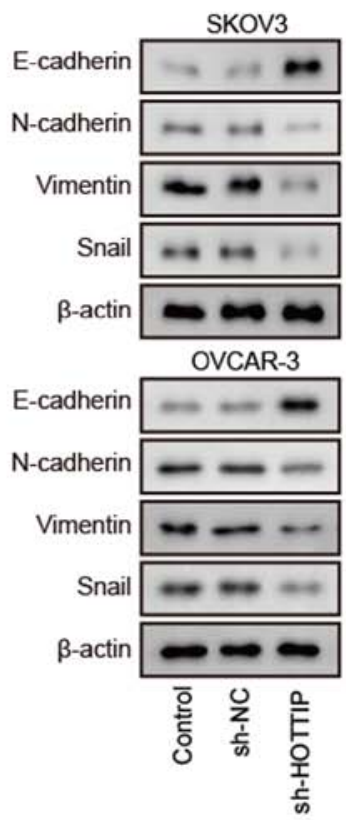

$\mathrm{F}$

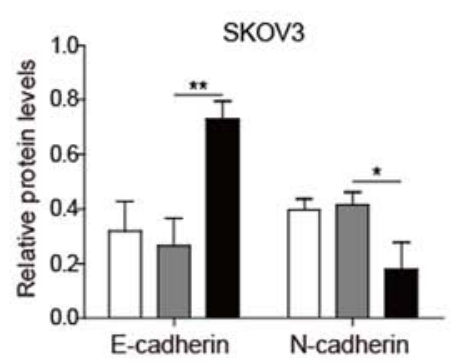

OVCAR-3

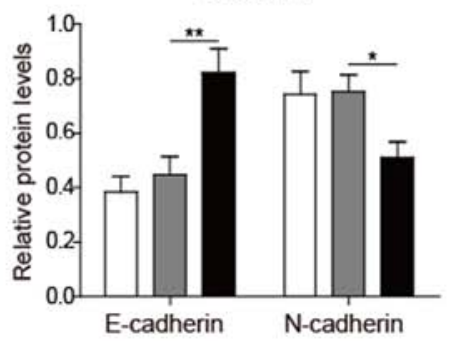

B
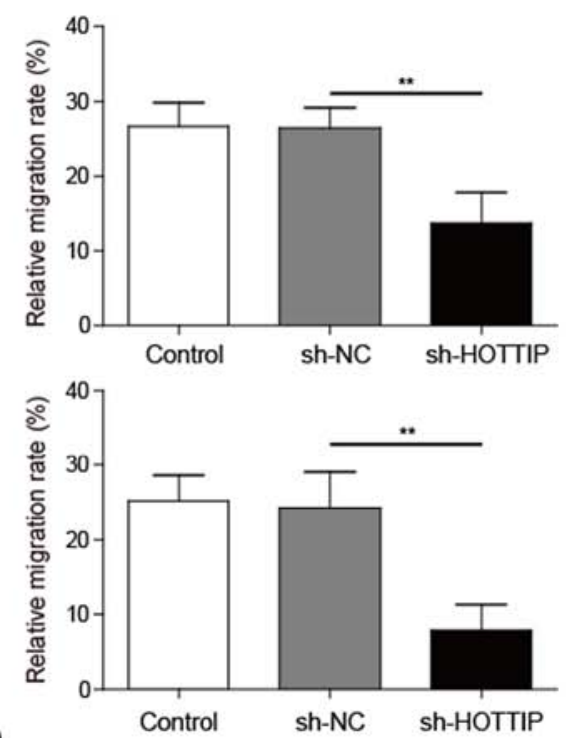

D

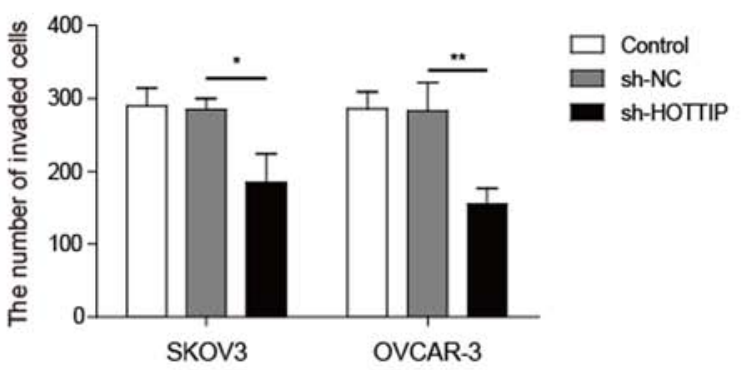

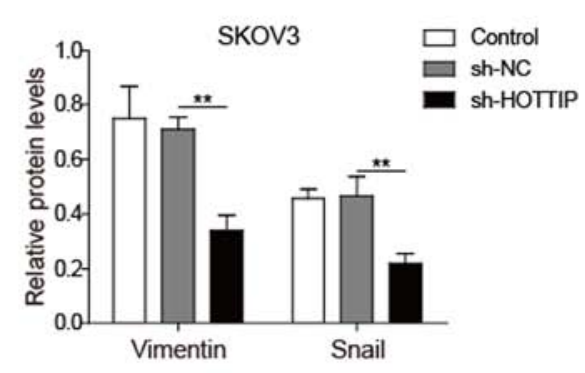

OVCAR-3

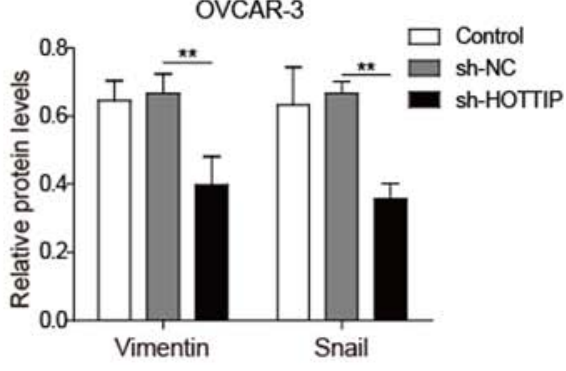

Figure 3. Knockdown of HOTTIP suppresses the migration, invasion and EMT of ovarian cancer cells. (A and B) Wound healing assay was conducted to determine the cell migration in SKOV3 and OVCAR-3 cells transfected with sh-HOTTIP. Scale bar=100 $\mu \mathrm{m}$. (C and D) SKOV3 and OVCAR-3 cells were transfected with sh-HOTTIP, and cell invasive ability was demonstrated using a Transwell invasion assay. Scale bar=100 $\mu$ m. (E and F) Differences among EMT marker expression in SKOV3 and OVCAR-3 cells transfected with sh-HOTTIP were detected by western blotting. The data are presented as the mean \pm SD of three independent experiments. ${ }^{*} \mathrm{P}<0.05,{ }^{* *} \mathrm{P}<0.01$. HOTTIP, HOXA distal transcript antisense RNA; EMT, epithelial-mesenchymal transition; sh, short hairpin; NC, negative control.

metastasis-associated cell behaviors were assessed in vitro using wound healing and Transwell assays. Wound healing assay results demonstrated that knockdown of HOTTIP reduced the migration of $\mathrm{OC}$ cells compared with that in cells transfected with sh-NC (Fig. 3A and B). Cancer cell invasion was also reduced by HOTTIP knockdown compared with that 
A

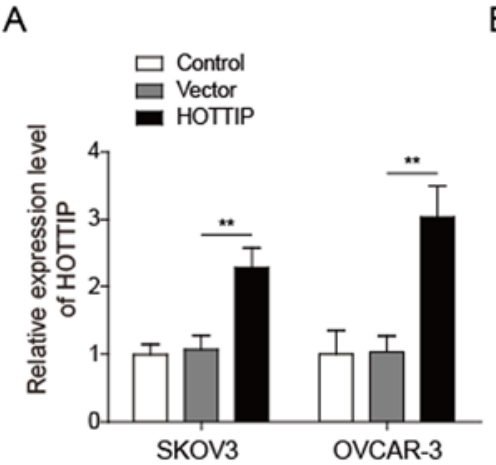

D

$\mathrm{F}$
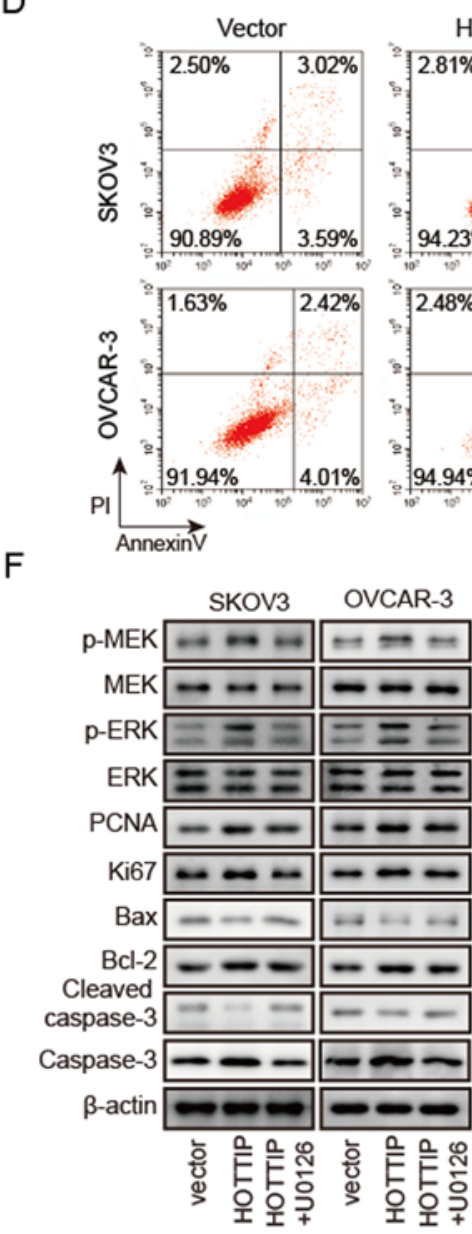

B

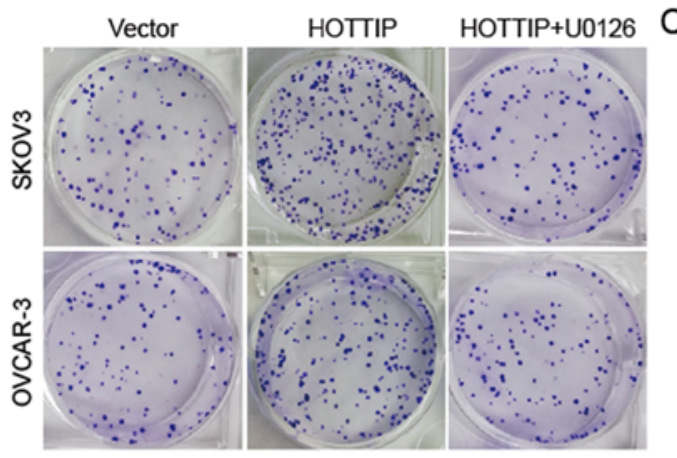

E

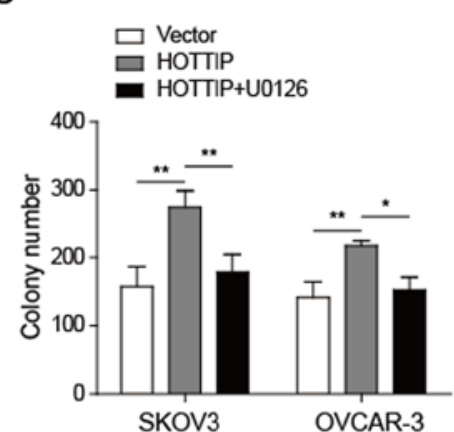

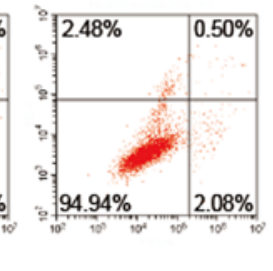

G
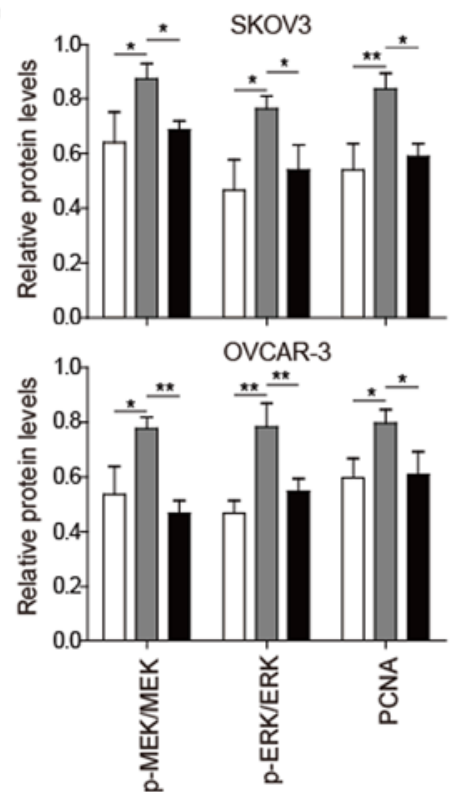

HOTTIP+U0126
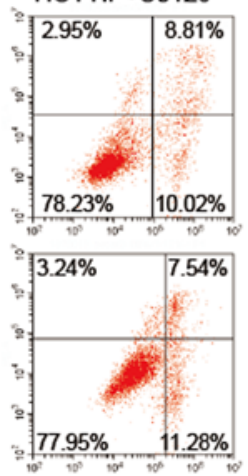
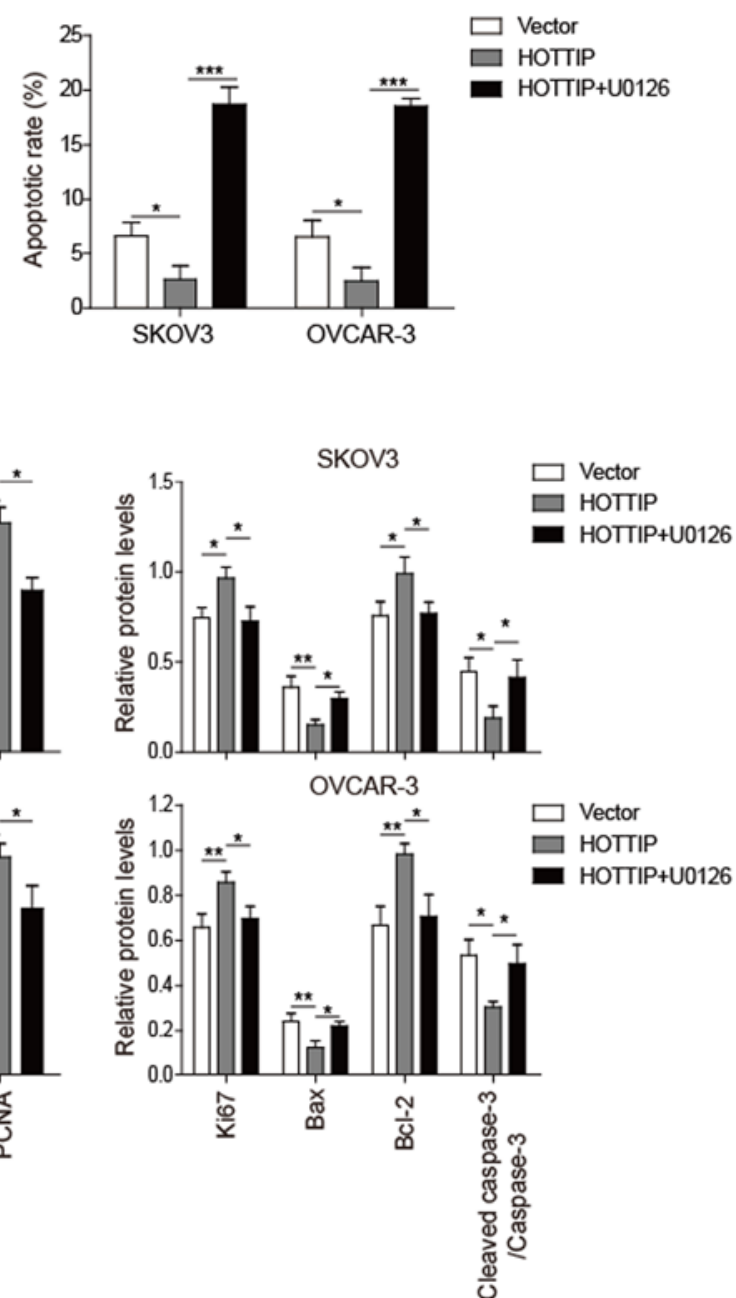

Figure 4. MEK/ERK pathway is involved in the HOTTIP-induced proliferation of ovarian carcinoma cells. (A) HOTTIP expression levels in SKOV3 and OVCAR-3 cells following transfection with pcDNA3.1-HOTTIP or vector were measured by RT-qPCR. (B and C) Colony formation of SKOV3 and OVCAR-3 cells following transfection with pcDNA3.1-HOTTIP and treatment with $10 \mu \mathrm{M}$ U0126 simultaneously. (D and E) Apoptosis was determined by flow cytometry in SKOV3 and OVCAR-3 cells following transfection with pcDNA3.1-HOTTIP and treatment with $10 \mu \mathrm{M} \mathrm{U0126.} \mathrm{(F} \mathrm{and} \mathrm{G)} \mathrm{Western} \mathrm{blotting} \mathrm{analysis} \mathrm{of}$ the expression of proliferation factors (PCNA and ki67) and apoptosis-associated proteins (cleaved caspase 3, Bax and Bcl-2) in SKOV3 and OVCAR-3 cells following transfection with pcDNA3.1-HOTTIP and treatment with $10 \mu \mathrm{M}$ U0126. The data are presented as the mean \pm SD of three independent experiments. ${ }^{*} \mathrm{P}<0.05,{ }^{* *} \mathrm{P}<0.01,{ }^{* * *} \mathrm{P}<0.001$. MEK, mitogen-activated protein kinase kinase; HOTTIP, HOXA distal transcript antisense RNA; RT-qPCR, reverse transcription-quantitative PCR; PCNA, proliferating cell nuclear antigen; p-, phosphorylated; PI, propidium iodide.

in the control shRNA group as detected by the Transwell assay (Fig. 3C and D). These results demonstrated that HOTTIP may exert an oncogenic role in $\mathrm{OC}$ by facilitating cell migration and invasion.
EMT is associated with tumor cell invasion and metastasis (15). Epithelial tumors become more aggressive during EMT, which is associated with the upregulation of mesenchymal protein markers, including vimentin and $\mathrm{N}$-cadherin, and the 
A
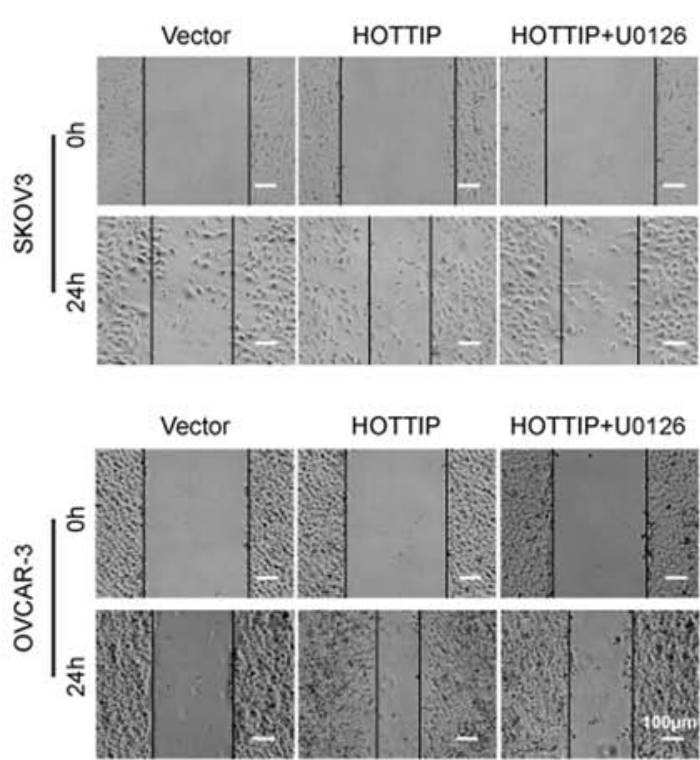

C

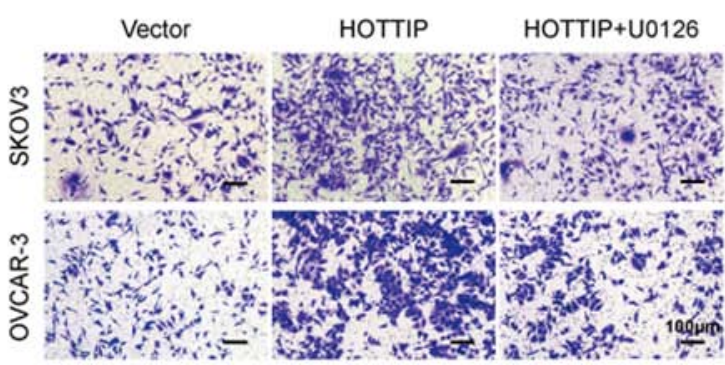

$E$

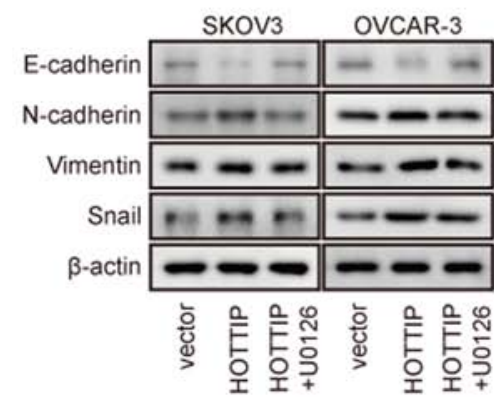

$\mathrm{F}$

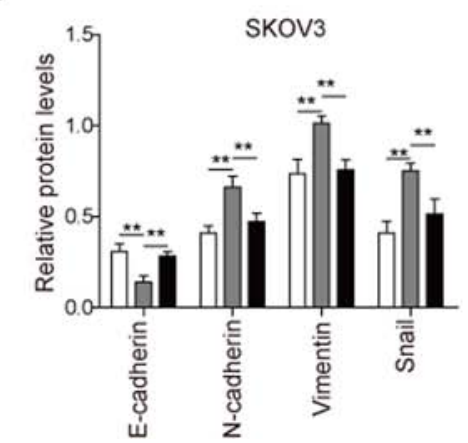

B

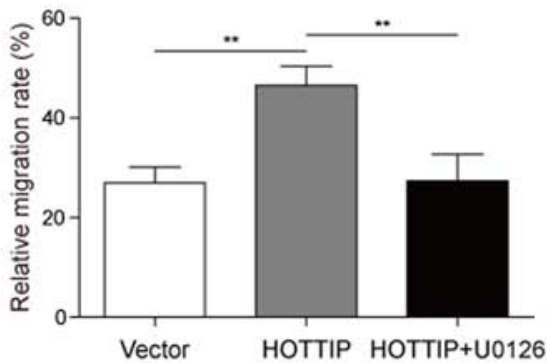

D
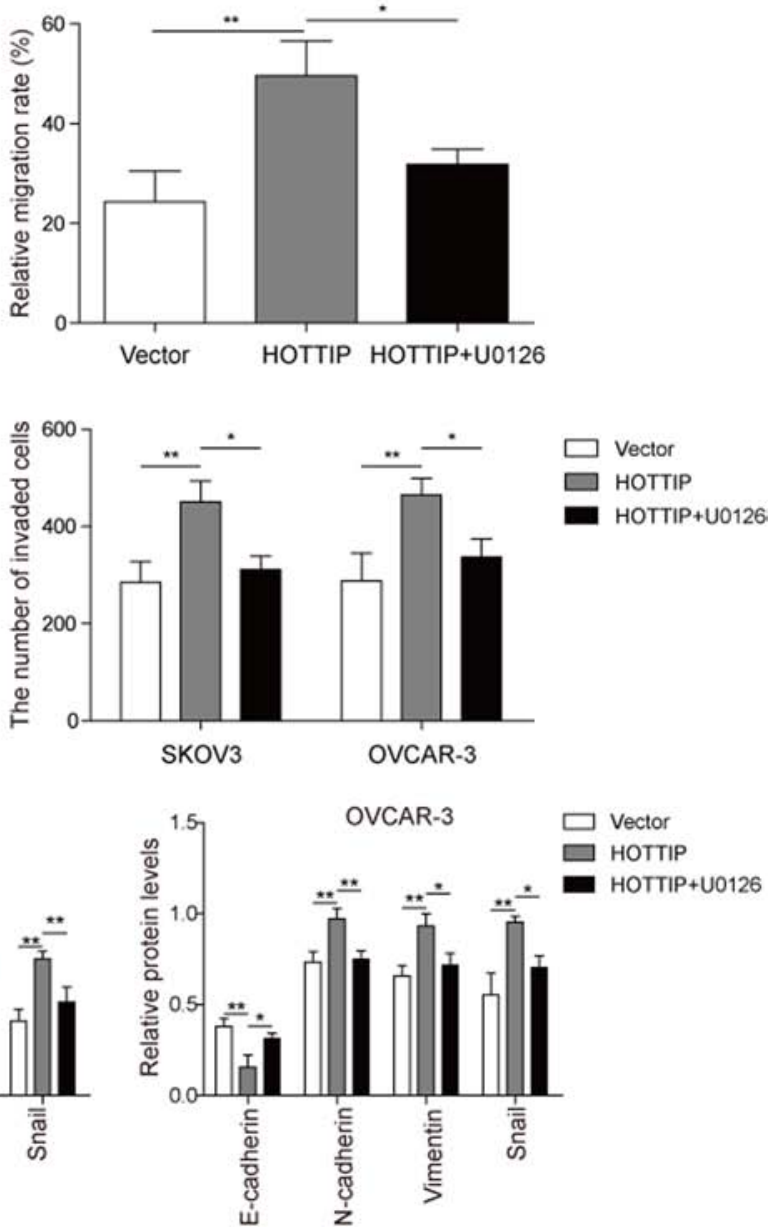

Figure 5. MEK/ERK pathway is involved in the HOTTIP-induced ovarian carcinoma cell invasion and migration. (A and B) Wound healing assays of SKOV3 and OVCAR-3 cells following transfection with pcDNA3.1-HOTTIP and treatment with $10 \mu \mathrm{M}$ U0126. (C and D) Transwell invasion assay of SKOV3 and OVCAR-3 cells following transfection with pcDNA3.1-HOTTIP and treatment with $10 \mu \mathrm{M}$ U0126. (E and F) Differences among epithelial-mesenchymal transition marker expression in SKOV3 and OVCAR-3 cells following transfection with pcDNA3.1-HOTTIP and treatment with $10 \mu \mathrm{M}$ U0126 detected by western blotting. The data are presented as the mean $\pm \mathrm{SD}$ of three independent experiments. ${ }^{*} \mathrm{P}<0.05,{ }^{* *} \mathrm{P}<0.01$. MEK, mitogen-activated protein kinase kinase; HOTTIP, HOXA distal transcript antisense RNA.

downregulation of epithelial markers, such as E-cadherin (16). In the present study, HOTTIP knockdown notably elevated E-cadherin and reduced N-cadherin, vimentin and Snail expression in SKOV3 and OVCAR-3 cells compared with that in cells transfected with sh-NC (Fig. 3E and F). These results suggested that HOTTIP may promote the migration and invasion of OC cells via EMT.

MEK/ERK pathway is involved in the HOTTIP-induced proliferation of $O C$ cells. HOTTIP serves crucial roles in OC cell proliferation and apoptosis (11), and HOTTIP knockdown significantly affected MEK and ERK phosphorylation in OC cells. To further confirm that HOTTIP regulated OC cell proliferation and apoptosis through the MEK/ERK pathway, SKOV3 and OVCAR-3 cells were transfected with pcDNA3.1-HOTTIP and treated with the MEK1/2-specific inhibitor U0126 simultaneously. The mRNA expression level of HOTTIP was increased following transfection with pcDNA3.1-HOTTIP in SKOV3 and OVCAR-3 cells compared with that in cells transfected with an empty vector (Fig. 4A). HOTTIP overexpression promoted OC cell colony formation, which was reversed by U0126 (Fig. 4B and C). In addition, the apoptotic rate of OC cells was decreased when HOTTIP was overexpressed and elevated in the presence of U0126 compared 
with the HOTTIP group, as demonstrated by Annexin V/PI staining (Fig. 4D and E). Additionally, when HOTTIP was overexpressed, the phosphorylation levels of MEK and ERK were increased, the protein levels of PCNA, ki67 and Bcl-2 were upregulated, and the levels of cleaved caspase- 3 and Bax were downregulated in SKOV3 and OVCAR-3 cells compared with those in the cells transfected with an empty vector (Fig. 4F and G). U0126 inhibited the HOTTIP-induced MEK and ERK phosphorylation and PCNA, ki67 and Bcl-2 expression, and decreased the levels of cleaved caspase-3 and Bax in HOTTIP-overexpressing OC cells. These results suggested that the MEK/ERK pathway was associated with HOTTIP-induced OC cell proliferation and apoptosis.

MEK/ERK pathway participates in the HOTTIP-induced invasion and migration of OC cells. As HOTTIP serves important roles in OC migration and EMT (10-11), the present study further investigated whether the MEK/ERK signaling pathway was involved in the HOTTIP-mediated OC cell migration and EMT. Overexpression of HOTTIP promoted the migration and invasion of OC cells compared with those of cells transfected with the empty vector, which was demonstrated by the wound healing (Fig. 5A and B) and Transwell (Fig. 5C and D) assays. As presented in Fig. 5A-D, the MEK1/2 inhibitor U0126 significantly inhibited the HOTTIP-induced OC cell migration and invasion, which suggested that the MEK/ERK pathway served a role in HOTTIP-regulated OC cell migration. HOTTIP overexpression downregulated the expression of the epithelial marker E-cadherin and upregulated the expression of the mesenchymal markers $\mathrm{N}$-cadherin, vimentin and Snail in SKOV3 and OVCAR-3 cells compared with those in vector-transfected cells; however, HOTTIP-induced OC cell EMT was significantly reversed by U0126 (Fig. 5E and F). These results suggested that HOTTIP promoted OC cell EMT via a mechanism involving the activation of the MEK/ERK signaling pathway.

\section{Discussion}

OC is a serious threat to female health. Previous studies have demonstrated that a number of IncRNAs are involved in the development of OC (17-19), including lncRNA HOTTIP, but the underlying mechanism remains to be elucidated. The results of the present study revealed that HOTTIP may be important for OC proliferation and invasion, and that the cancer-promoting features of HOTTIP could be reversed by MEK1/2 inhibitor; this suggested that HOTTIP may promote the proliferation and invasion of $\mathrm{OC}$ cells by activating the MEK/ERK pathway.

The function of lncRNA HOTTIP has been investigated in multiple types of cancer, including esophageal squamous cell (10) and thyroid (20) carcinoma, colorectal (21) and nasopharyngeal (22) cancer cells. The majority of studies conclude that HOTTIP serves oncogenic roles $(10,20-22)$. The AKT survival pathway is upregulated by HOTTIP in various types of cancer cells, including mammary (23), endometrial (24) and renal (25) cancer cells. In addition to cancer cells, HOTTIP has been identified to regulate endothelial cell proliferation and migration (26). A recent study has suggested that HOTTIP is an indicator of OC prognosis and facilitates
OC cell proliferation and invasion (11), but the underlying mechanism remains to be elucidated. The present study demonstrated that HOTTIP knockdown inhibited, whereas HOTTIP overexpression promoted MEK and ERK phosphorylation in OC cells compared with that in the respective negative control groups. The MEK/ERK pathway regulates a number of important cellular functions including proliferation, differentiation, survival and migration (27). Previous studies have demonstrated that over-activation of MEK/ERK signaling is involved in the oncogenesis of human cancers, which makes it an appealing target for anticancer therapeutics (28-31). The MEK/ERK pathway serves important roles in regulating gastric cancer (29), retinoblastoma (30) and pancreatic cancer (31) oncogenesis. A recent study has also revealed that the MEK/ERK cascade may be a promising target to inhibit human OC cells via inducing apoptosis and cell cycle arrest (32). The present study identified that HOTTIP was involved in the regulation of $\mathrm{OC}$ cell proliferation, apoptosis and invasion. The OC-promoting properties of HOTTIP were reversed by a specific inhibitor of MEK1/2, which suggested that HOTTIP promoted the proliferation and invasion of OC cells by activating the MEK/ERK signaling pathway.

Although a number of studies have revealed the important role of lncRNAs in regulating different physiological and pathological processes, the underlying mechanisms are mostly uncharacterized (33). The sponge or decoy function of IncRNA on micro (mi)RNAs has been revealed (34). The results of the present study suggested that IncRNA HOTTIP promoted OC via the MEK/ERK pathway; however, no evidence was observed to identify whether HOTTIP directly phosphorylated MEK or ERK. A recent study has demonstrated that miRNA-145 inhibits the MEK/ERK pathway by directly regulating ERK1/2 expression (35). miRNA-30a also suppresses MEK/ERK signaling by targeting K-Ras mRNA (36). HOTTIP may regulate the activation of the MEK/ERK pathway indirectly by interacting with other mRNA or miRNAs; the specific regulatory mechanism of lncRNA HOTTIP on MEK/ERK signaling transduction in $\mathrm{OC}$ needs to be further investigated.

Tumor cells may be transformed into cancer stem cell-like cells through EMT and lead to radiotherapy and chemotherapy resistance, angiogenesis and distant metastasis, which lead to the poor prognosis of tumors (37). EMT is accompanied by upregulation of mesenchymal markers, such as N-cadherin and vimentin, and downregulation of epithelial markers, including E-cadherin, and is expected to be an important target in cancer treatment (16). The results of the present study identified that the levels of the mesenchymal protein markers were downregulated by HOTTIP knockdown and upregulated by HOTTIP overexpression, whereas those of the epithelial protein marker E-cadherin were upregulated by HOTTIP knockdown and downregulated by HOTTIP overexpression. These results suggested that HOTTIP may promote the migration and invasion of OC cells via EMT. In addition, the HOTTIP-promoted changes in EMT marker expression in OC cells were reversed by U0126, which suggested that HOTTIP promoted OC cell EMT via a mechanism involving the activation of the MEK/ERK signaling pathway.

In conclusion, HOTTIP promoted the proliferation, invasion and EMT of OC cells by activating the MEK/ERK pathway. 
These results indicated that HOTTIP and the MEK/ERK pathway axis may contribute to OC tumorigenesis and metastasis, and that they may be potential targets for the diagnosis and treatment of OC.

\section{Acknowledgements}

Not applicable.

\section{Funding}

This work was supported by Shaoguan Science and Technology Planning Project in 2019 (grant no. 2019sn011).

\section{Availability of data and materials}

All data generated or analyzed during this study are included in this published article.

\section{Authors' contributions}

JL and ZL conceived and designed the present study. JL and $\mathrm{HH}$ provided administrative support. YL and ZL provided study materials. YL performed literature research and analyzed literature suitability. FL and LZ performed the experiments. JL, ZL and $\mathrm{HH}$ performed data analysis and interpretation. All authors wrote the manuscript. All authors read and approved the final manuscript.

\section{Ethics approval and consent to participate}

Not applicable.

\section{Patient consent for publication}

Not applicable.

\section{Competing interests}

The authors declare that they have no competing interests.

\section{References}

1. Torre LA, Trabert B, DeSantis CE, Miller KD, Miller KD, Samimi G, Runowicz CD, Gaudet MM, Jemal A and Siegel RL: Ovarian cancer statistics, 2018. Ca Cancer J Clin 68: 284-296, 2018

2. Cortez AJ, Tudrej P, Kujawa KA and Lisowska KM: Advances in ovarian cancer therapy. Cancer Chemother Pharmacol 81: 17-38, 2018.

3. Ma DD, Yuan LL and Lin L: LncRNA HOTAIR contributes to the tumorigenesis of nasopharyngeal carcinoma via up-regulating FASN. Eur Rev Med Pharmacol Sci 21: 5143-5152, 2017.

4. Nie GH, Li Z, Duan HF, Luo L, Hu HY, Yang WQ, Nie LP, Zhu RF, Chen XF and Zhang W: lncRNA C22orf32-1 contributes to the tumorigenesis of nasopharyngeal carcinoma. Oncol Lett 13: 4487-4492, 2017.

5. Qiu JJ, Lin YY, Ding JX, Feng WW, Jin HY and Hua KQ: Long non-coding RNA ANRIL predicts poor prognosis and promotes invasion/metastasis in serous ovarian cancer. Int J Oncol 46: 2497-2505, 2015.

6. Richards EJ, Permuth-Wey J, Li Y, Chen YA, Coppola D, Reid BM, Lin HY, Teer JK, Berchuck A, Birrer MJ, et al: A functional variant in HOXA11-AS, a novel long non-coding RNA, inhibits the oncogenic phenotype of epithelial ovarian cancer. Oncotarget 6: 34745-34757, 2015.
7. Bhatlekar S, Fields JZ and Boman BM: HOX genes and their role in the development of human cancers. J Mol Med (Berl) 92: 811-823, 2014.

8. Wang KC, Yang YW, Liu B, Sanyal A, Corces-Zimmerman R, Chen Y, Lajoie BR, Protacio A, Flynn RA, Gupta RA, et al: A long noncoding RNA maintains active chromatin to coordinate homeotic gene expression. Nature 472: 120-124, 2011.

9. Fu ZQ, Chen CH, Zhou QB, Wang YX, Zhao Y, Zhao X, Li W, Zheng S, Ye H, Wang L, et al: LncRNA HOTTIP modulates cancer stem cell properties in human pancreatic cancer by regulating HOXA9. Cancer Lett 410: 68-81, 2017.

10. Chen X, Han H, Li Y, Zhang Q, Mo K and Chen S: Upregulation of long noncoding RNA HOTTIP promotes metastasis of esophageal squamous cell carcinoma via induction of EMT. Oncotarget 7: 84480-84485, 2016.

11. Zou T, Wang PL, Gao Y and Liang WT: Long noncoding RNA HOTTIP is a significant indicator of ovarian cancer prognosis and enhances cell proliferation and invasion. Cancer Biomark 25: 133-139, 2019.

12. Xu X, Tian J and Li QY: Downregulation of HOTTIP regulates insulin secretion and cell cycle in islet $\beta$ cells via inhibiting MEK/ERK pathway. Eur Rev Med Pharmacol Sci 22: 4962-4968, 2018.

13. Livak KJ and Schmittgen TD: Analysis of relative gene expression data using real-time quantitative PCR and the 2(-Delta Delta C(T)) method. Methods 25: 402-408, 2001.

14. McCubrey JA, Steelman LS, Chappell WH, Abrams SL, Wong EW, Chang F, Lehmann B, Terrian DM, Milella M, Tafuri A, et al: Roles of the Raf/MEK/ERK pathway in cell growth, malignant transformation and drug resistance. Biochim Biophys Acta 1773: 1263-1284, 2007.

15. Wang S, Yan Y, Cheng Z, Hu Y and Liu T: Sotetsuflavone suppresses invasion and metastasis in non-small-cell lung cancer A549 cells by reversing EMT via the TNF- $\alpha / N F-\kappa B$ and PI3K/AKT signaling pathway. Cell Death Discov 4: 26, 2018.

16. Kang YB and Massagué J: Epithelial-mesenchymal transitions: Twist in development and metastasis. Cell 118: 277-279, 2004.

17. Nikpayam E, Tasharrofi B, Sarrafzadeh S and Ghafouri-Fard S: The role of long non-coding RNAs in ovarian cancer. Iran Biomed J 21: 3-15, 2017.

18. Fu Y, Biglia N, Wang Z, Shen Y, Risch HA, Lu L, Canuto EM, Jia W, Katsaros D and $\mathrm{Yu} \mathrm{H}$ : Long non-coding RNAs, ASAP1-IT1, FAM215A, and LINC00472, in epithelial ovarian cancer. Gynecol Oncol 143: 642-649, 2016.

19. Vafaee F, Colvin EK, Mok SC, Howell VM and Samimi G: Functional prediction of long non-coding RNAs in ovarian cancer-associated fibroblasts indicate a potential role in metastasis. Sci Rep 7: 10374, 2017.

20. Yuan Q, Liu Y, Fan Y, Liu Z, Wang X, Jia M, Geng Z, Zhang J and $\mathrm{Lu}$ X: LncRNA HOTTIP promotes papillary thyroid carcinoma cell proliferation, invasion and migration by regulating miR- 637 . Int J Biochem Cell Biol 98: 1-9, 2018.

21. Liu T, Yu T, Hu H and He K: Knockdown of the long non-coding RNA HOTTIP inhibits colorectal cancer cell proliferation and migration and induces apoptosis by targeting SGK1. Biomed Pharmacother 98: 286-296, 2018.

22. Shen M, Li M and Liu J: Long noncoding RNA HOTTIP promotes nasopharyngeal cancer cell proliferation, migration, and invasion by inhibiting miR-4301. Med Sci Monit 25: 778-785, 2019.

23. Gao W, Wu XL, Li DZ and Liu HD: HOTTIP participates in mammary cancer by promoting cell proliferation via PI3K/AKT pathway. Eur Rev Med Pharmacol Sci 22: 4181-4187, 2018.

24. Guan Q, Zhang Q, Zhang C, Liu Q and Ren QL: HOTTIP regulates progression of endometrial cancer via activating PI3K/AKT pathway. Eur Rev Med Pharmacol Sci 22: 3727-3733, 2018.

25. Su Y, Lu J, Chen X, Liang C, Luo P, Qin C and Zhang J: Long non-coding RNA HOTTIP affects renal cell carcinoma progression by regulating autophagy via the PI3K/Akt/Atg13 signaling pathway. J Cancer Res Clin Oncol 145: 573-588, 2019.

26. Liao B, Chen R, Lin F, Mai A, Chen J, Li H, Xu Z and Dong S: Long noncoding RNA HOTTIP promotes endothelial cell proliferation and migration via activation of the Wnt/ $\beta$-catenin pathway. J Cell Biochem 119: 2797-2805, 2018.

27. Guo L, Bai Y, Ji S and Ma H: MicroRNA-98 suppresses cell growth and invasion of retinoblastoma via targeting the IGF1R/k-Ras/Raf/MEK/ERK signaling pathway. Int J Oncol 54: 807-820, 2019 
28. Yu ZT, Ye SQ, Hu GY, Lv M, Tu Z, Zhou K and Li QB: The RAF-MEK-ERK pathway: Targeting ERK to overcome obstacles of effective cancer therapy. Future Med Chem 7: 269-289, 2015.

29. Zhang HZ, Jiang HJ, Zhang HX, Liu JC, Hu X and Chen L: Ribophorin II potentiates P-glycoprotein- and ABCG2-mediated multidrug resistance via activating ERK pathway in gastric cancer. Int J Biol Macromol 128: 574-582, 2019.

30. Yu FF, Pang GL and Zhao GQ: ANRIL acts as onco-lncRNA by regulation of microRNA-24/c-Myc, MEK/ERK and Wnt/ $\beta$-catenin pathway in retinoblastoma. Int J Biol Macromol 128: 583-592, 2019

31. Wang J, Guo XJ, Xie CC and Jiang JX: KIF15 promotes pancreatic cancer proliferation via the MEK-ERK signalling pathway. Br J Cancer 117: 245-255, 2017.

32. Hua F, Li CH, Chen XG and Liu XP: Daidzein exerts anticancer activity towards SKOV3 human ovarian cancer cells by inducing apoptosis and cell cycle arrest, and inhibiting the Raf/MEK/ERK cascade. Int J Mol Med 41: 3485-3492, 2018.

33. Durruthy-Durruthy J, Sebastiano V, Wossidlo M, Cepeda D, Cui J, Grow EJ, Davila J, Mall M, Wong WH, Wysocka J, et al: The primate-specific noncoding RNA HPAT5 regulates pluripotency during human preimplantation development and nuclear reprogramming. Nat Genet 48: 44-52, 2016.
34. Paraskevopoulou MD and Hatzigeorgiou AG: Analyzing MiRNA-LncRNA interactions. Methods Mol Biol 1402: 271-286, 2016.

35. Jafarnejad SM, Chapat C, Matta-Camacho E, Gelbart IA, Hesketh GG, Arguello M, Garzia A, Kim SH, Attig J, Shapiro M, et al: Translational control of ERK signaling through miRNA/4EHP-directed silencing. Elife 7: e35034, 2018.

36. Zhou K, Luo X, Wang Y, Cao D and Sun G: MicroRNA-30a suppresses tumor progression by blocking Ras/Raf/MEK/ERK signaling pathway in hepatocellular carcinoma. Biomed Pharmacother 93: 1025-1032, 2017.

37. Lamouille S, Xu J and Derynck R: Molecular mechanisms of epithelial-mesenchymal transition. Nat Rev Mol Cell Biol 15: 178-196, 2014. Attribution-NonCommercial-NoDerivatives 4.0 International (CC BY-NC-ND 4.0) License. 